\title{
Efficacy of add-on mepolizumab in adolescents with severe eosinophilic asthma
}

\author{
Steven W. Yancey ${ }^{1 *} \mathbb{D}$, Hector G. Ortega ${ }^{2,4}$, Oliver N. Keene ${ }^{3}$ and Eric S. Bradford ${ }^{1}$
}

\begin{abstract}
Adolescents (12-17 years of age) with severe eosinophilic asthma experience frequent exacerbations and reduced lung function leading to poor health-related quality of life. Mepolizumab is approved for add-on maintenance therapy in patients with severe eosinophilic asthma $\geq 6$ years of age in the $E U$ and $\geq 12$ years of age in other regions (including the USA), based on a Phase II/III program demonstrating reduced exacerbation rates with 4-weekly treatment. A total of 34 adolescent patients were recruited across the Phase III mepolizumab trials. Consistent with outcomes in the overall population, there was a reduction in the annual rate of clinically significant exacerbations, along with a reduction in blood eosinophil counts in response to mepolizumab in adolescent patients. The safety profile in adolescent patients was consistent with that seen in the overall population. Data from the Phase III clinical development program provide evidence for comparable efficacy and safety of mepolizumab between adolescents with severe eosinophilic asthma and the overall population.

Clinical trial registration DREAM, NCT01000506 [MEA112997]; MENSA, NCT01691521 [MEA115588]; SIRIUS, NCT01691508 [MEA115575]; MUSCA, NCT02281318 [200862]; COSMOS, NCT01842607 [MEA115661].
\end{abstract}

Keywords: Adolescent, Asthma control, Eosinophils, Exacerbations, Mepolizumab, Severe eosinophilic asthma

\section{Dear editor,}

Asthma is a substantial health problem among adolescents (12-17 years of age) [1]. Despite receiving maximum standard of care therapy, adolescents with severe asthma and eosinophilic inflammation experience poor symptom control, reduced lung function and frequent exacerbations, often leading to compromised health-related quality of life [2-4]. In particular, frequent exacerbations are disabling for the patient and their caregivers/family, typically requiring treatment with high doses of oral corticosteroids (OCS) and, in many cases, hospital admission [5, 6]. Regular use of OCS ( $>7 \mathrm{mg} /$ day) is associated with a number of well-documented side effects, one of which is growth impairment, a particular concern for adolescents [7]. Although the prevalence of adolescents within the severe eosinophilic asthma population is low (approximately $4 \%$

\footnotetext{
*Correspondence: steve.w.yancey@gsk.com

${ }^{1}$ Respiratory Therapeutic Area, GSK, 5 Moore Drive, PO Box 13398,

Research Triangle Park, NC 27709, USA

Full list of author information is available at the end of the article
}

when based on recruitment to clinical trials) $[8,9]$, the disease burden for this sub-population is substantial [6]. Evidence is provided by the observation of more frequent hospitalizations required for adolescents with severe asthma than for adult patients with severe asthma [5, 6]. Furthermore asthma also has a significant impact in adolescents due to days lost at school [10]. Poor self-care is an important contributory factor, as well as treatment compliance [11-13].

Several biologic therapies are now available for patients with severe asthma who were previously without effective treatment options. Mepolizumab, an anti-interleukin (IL)-5 therapy, was approved in 2015 for add-on maintenance treatment of patients with severe asthma $\geq 12$ years of age and with an eosinophilic phenotype; in 2018 the EU license was extended to include patients with severe asthma $\geq 6$ years of age. The Phase II/III program for mepolizumab showed that mepolizumab administered once every 4 weeks reduced exacerbation rates and OCS use, and improved quality of life, compared with placebo in patients $\geq 12$ years of age with severe eosinophilic asthma [14-17]. Here we 
present data from the adolescent population enrolled in this Phase II/III program.

Due to the low prevalence of severe eosinophilic asthma in adolescents, recruitment of adolescents into the Phase II/III mepolizumab trials was challenging. However, a total of 34 adolescent patients $\geq 12-17$ years of age were randomized across 4 studies: the 32-week MENSA study $(\mathrm{n}=25$; NCT01691521); the 24-week MUSCA study $(\mathrm{n}=9$; NCT02281318); the 52-week DREAM study ( $\mathrm{n}=1$; NCT01000506); and the 24-week SIRIUS study $(\mathrm{n}=2$; NCT01691508). In these trials, every 4 weeks, patients with severe eosinophilic asthma received either placebo or 75,250 or $750 \mathrm{mg}$ intravenous (IV) mepolizumab (DREAM); placebo or $75 \mathrm{mg}$ IV mepolizumab or $100 \mathrm{mg}$ subcutaneous (SC) mepolizumab (MENSA); or placebo or $100 \mathrm{mg}$ mepolizumab (SIRIUS/MUSCA). Full details of the inclusion/exclusion criteria and treatment schedules have been previously published [14-17].

Adolescents in the MENSA study (the study with the largest recruitment of adolescents) displayed similar baseline exacerbation rates, Asthma Control Questionnaire (ACQ) scores and blood eosinophil counts compared with the overall population. However, in the adolescent population, asthma duration was shorter (as expected), a numerically higher proportion of patients were atopic and experienced hospitalizations associated with exacerbations, and a numerically lower proportion of patients were using maintenance OCS at baseline (Table 1).

Eosinophilia has been defined as a key phenotypic characteristic of patients with severe eosinophilic asthma
$[16,18]$. While the proportion of patients with atopy was numerically different between the adolescent group and the overall population, the blood eosinophil count appeared similar. The Phase III mepolizumab program demonstrated selective inhibition of eosinophilic inflammation and reduction in the number of eosinophils in both sputum and blood in patients treated with mepolizumab [14, 16, 17]. A reduction in blood eosinophil counts in response to mepolizumab treatment was also demonstrated in the adolescent population in MENSA from Week 4; the count reached 40 cells/ $\mu \mathrm{L}$ at Week 32, which was consistent with the overall population. Furthermore, a population pharmacokinetic (PK) analysis of MENSA data indicated no effect of age on the PK of mepolizumab, with adolescents displaying plasma concentrations consistent with adults and predicted clearance within the range of the rest of the study population, irrespective of administration route (data not shown).

Blood eosinophil count was also shown to be a predictive biomarker for response to mepolizumab treatment, with reductions in eosinophil counts accompanied by reductions in clinically significant exacerbations [14, 16, 17]. In a post hoc subgroup analysis of the two studies that recruited adolescent patients in each randomized treatment group (MENSA and MUSCA), the adolescent population showed generally similar reductions in the annual rate of clinically significant exacerbations compared with patients $\geq 18$ years of age (Fig. 1). In a post hoc metaanalysis of patients from the MENSA and MUSCA trials, overall there was a $40 \%$ reduction in the annual rate of

Table 1 Baseline demographics and disease characteristics for patients in MENSA and in DREAM/MENSA/MUSCA/SIRIUS combined

\begin{tabular}{|c|c|c|c|c|c|c|}
\hline & \multicolumn{3}{|l|}{ MENSA } & \multicolumn{3}{|c|}{ DREAM/MENSA/MUSCA/SIRIUS } \\
\hline & $\begin{array}{l}12-17 \text { years } \\
(\mathrm{N}=25)\end{array}$ & $\begin{array}{l}\geq 18 \text { years } \\
(\mathrm{N}=551)\end{array}$ & $\begin{array}{l}\text { Overall population } \\
(N=576)\end{array}$ & $\begin{array}{l}12-17 \text { years } \\
(\mathrm{N}=37)\end{array}$ & $\begin{array}{l}\geq 18 \text { years } \\
(\mathrm{N}=1841)\end{array}$ & $\begin{array}{l}\text { Overall population } \\
(\mathrm{N}=1878)\end{array}$ \\
\hline Age, years, mean (SD) & $15(2)$ & $52(12)$ & $50(14)$ & $15(2)$ & $51(12)$ & $50(13)$ \\
\hline Asthma duration, years, mean (SD) & $9.6(4.2)$ & $20.4(13.9)$ & $19.9(13.8)$ & $10.3(3.9)$ & $19.6(14.3)$ & $19.5(14.2)$ \\
\hline Atopic ${ }^{\mathrm{a}}, \mathrm{n}(\%)$ & $18(72)$ & $252(46)$ & $270(47)$ & $28(76)$ & $853(46)$ & $881(47)$ \\
\hline Exacerbations in year prior to study, mean (SD) & $3.7(2.8)$ & $3.6(2.6)$ & $3.6(2.6)$ & $3.7(2.5)$ & $3.3(2.6)$ & $3.3(2.6)$ \\
\hline $\begin{array}{l}\text { Patients experiencing an exacerbation } \\
\text { requiring ED visit/hospitalization, } n \text { (\%) }\end{array}$ & $10(40)$ & $180(33)$ & $190(33)$ & $21(57)$ & $653(35)$ & $674(36)$ \\
\hline $\begin{array}{l}\text { Patients experiencing an exacerbation } \\
\text { requiring hospitalization, } \mathrm{n}(\%)\end{array}$ & $8(32)$ & $101(18)$ & 109 (19) & $13(35)$ & $406(22)$ & $419(22)$ \\
\hline ACQ score at baseline, mean (SD) & $1.9(1.1)$ & $2.2(1.2)$ & $2.2(1.2)$ & $1.9(1.2)$ & $2.3(1.2)$ & $2.3(1.2)$ \\
\hline Maintenance OCS use at baseline, n (\%) & $4(16)$ & $140(25)$ & $144(25)$ & $6(16)$ & $592(32)$ & $598(32)$ \\
\hline $\begin{array}{l}\text { Baseline blood eosinophil count, cells/ } \mu \mathrm{L} \text {, } \\
\text { geometric mean (SD logs) }\end{array}$ & $240(0.91)$ & $300(1.00)$ & $290(0.99)$ & $290(0.90)$ & $280(1.03)$ & $280(1.03)$ \\
\hline
\end{tabular}

a Atopy defined as testing $\geq 0.35 \mathrm{kU} / \mathrm{L}$ for house dust mite, dog dander, cat dander, or Alternaria alternate allergens

ACQ: Asthma control questionnaire; ED: emergency department; OCS: oral corticosteroids; SD: standard deviation 


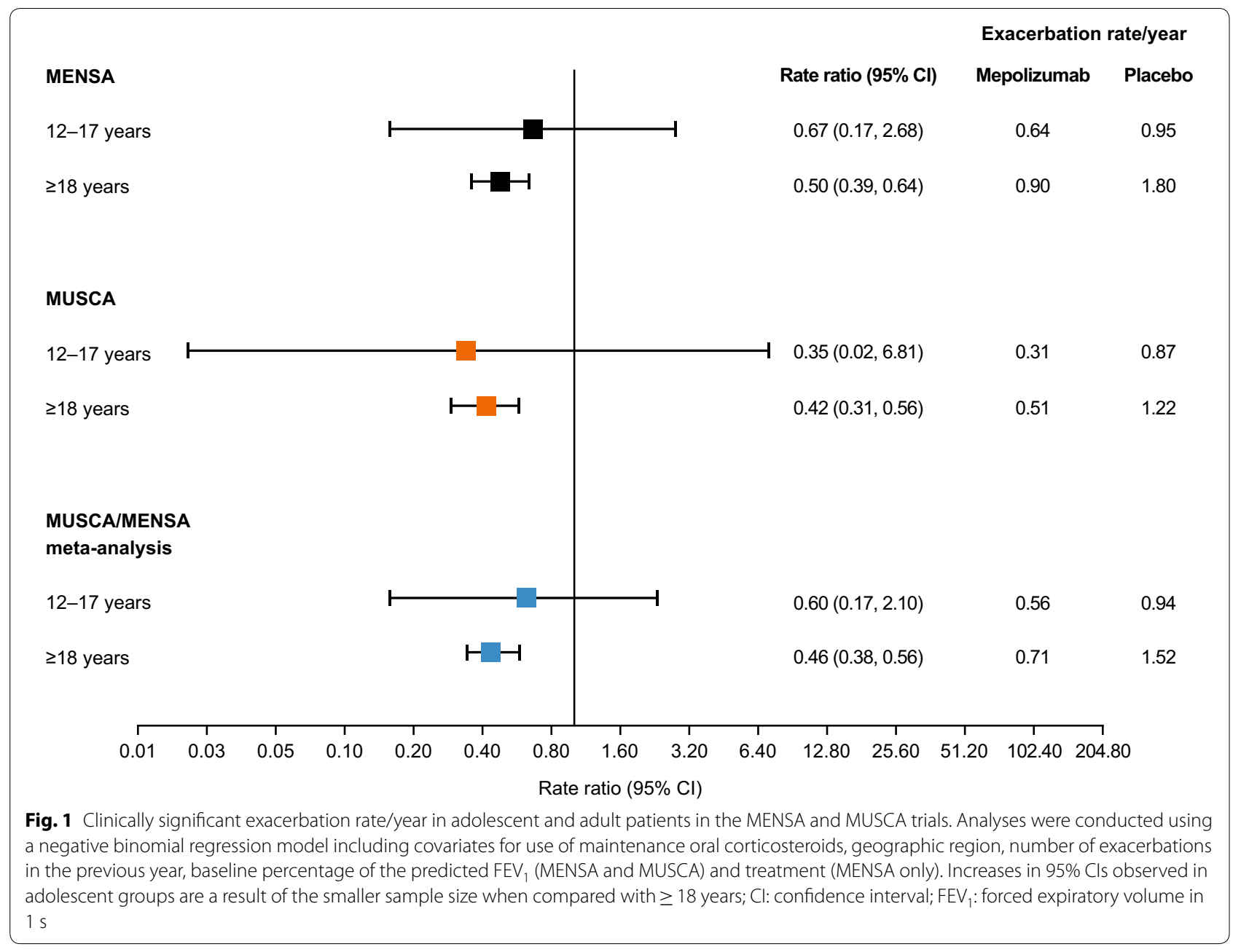

clinically significant exacerbations in the adolescent population, 12-17 years of age, consistent with the reduction shown in adult patients, $\geq 18$ years of age (Fig. 1). As these studies were not designed to detect differences between mepolizumab and placebo in the adolescent population, no formal tests of statistical significance were performed.

In terms of safety, over the course of the Phase III program, mepolizumab was shown to be well tolerated in the overall population [14-17], and the safety profile was similar in the adolescent population. The incidence and profile of adverse events (AEs) and serious AEs experienced by adolescents $(n=37)$ was similar to those reported in the overall populations in the primary studies (MENSA, MUSCA, DREAM, SIRIUS) [14-17]. There were no withdrawals due to AEs among adolescents receiving placebo or mepolizumab, and the most common AEs in this group were headache, nasopharyngitis, and upper abdominal pain. Five adolescent patients receiving placebo or mepolizumab reported serious AEs (asthma exacerbation $[\mathrm{n}=3]$, gastroenteritis rotavirus $[n=1]$, dyshidrotic eczema $[n=1]$ ); none of these AEs were considered to be treatment-related, and of these serious AEs, only one case of asthma exacerbation and one of dyshidrotic eczema was reported in patients receiving mepolizumab. Of the 37 adolescent patients enrolled in the primary studies, 26 entered COSMOS (NCT01842607) [19], a 52-week, open-label extension study of MENSA and SIRIUS in which all patients received SC mepolizumab $100 \mathrm{mg}$, and have long-term safety data available. Adolescent patients had a median of 12.1 months of exposure to mepolizumab $100 \mathrm{mg} \mathrm{SC}$, ranging from 2 to 20 months. In COSMOS, the $\mathrm{AE}$ and serious AE profile for adolescents remained similar to the overall population, with nasopharyngitis, sinusitis, and asthma the most commonly reported AEs. Five adolescent patients experienced serious AEs, the most commonly reported of which were asthma exacerbations $(\mathrm{n}=5 / 26 ; 19 \%)$. This is a numerically higher percentage than that observed in the overall COSMOS population 
for the serious $\mathrm{AE}$ of asthma exacerbation $(\mathrm{n}=38 / 651$; 6\%) [19]; however, this observation should be considered with caution as the adolescent sub-group was small.

Given the substantial unmet treatment need in adolescent patients with severe eosinophilic asthma, it is important to determine how biological therapies that have demonstrated efficacy in adult patients with severe eosinophilic asthma perform in the adolescent population. Although the adolescent population was small, data from the Phase III mepolizumab clinical development program provide evidence for comparable efficacy and safety of mepolizumab between adolescents with severe eosinophilic asthma and the overall population.

\section{Abbreviations \\ ACQ: Asthma Control Questionnaire; AE: adverse event; Cl: confidence interval; ED: emergency department; $\mathrm{FEV}_{1}$ : forced expiratory volume in 1 s; IL-5: interleukin-5; OCS: oral corticosteroids; PK: pharmacokinetic; SC: subcutaneous; SD: standard deviation.}

\section{Acknowledgements}

Editorial support (in the form of writing assistance, including development of the initial draft, assembling tables and figures, collating author comments, grammatical editing and referencing) was provided by Elizabeth Hutchinson, CMPP, PhD, at Fishawack Indicia Ltd, UK, and was funded by GSK. Statistical analysis was completed by Rob Price, at GSK.

\section{Authors' contributions}

SWY, HGO, ONK, and ESB contributed to the conception and design of the primary studies, the analysis and interpretation of the data, development of the manuscript and approval of the final draft to be published. ONK performed the statistical analysis for the manuscript. All authors read and approved the final manuscript.

\section{Funding}

The studies (DREAM [NCT01000506, MEA112997], MENSA [NCT01691521, MEA115588], SIRIUS [NCT01691508, MEA115575], MUSCA [NCT02281318, 200862], and COSMOS [NCT01842607, MEA115661]), the adolescent subgroup analysis of MENSA and MUSCA, and the post hoc meta-analysis of MENSA and MUSCA were funded by GSK. GSK had a role in the design of the analysis, data collection, data analysis, and data interpretation. The funder did not place any restrictions on access to the data or statements made in the manuscript. The decision to submit for publication was that of the authors alone.

\section{Availability of data and materials}

Anonymized individual participant data and study documents for the original studies can be requested for further research from http://www.clinicalstudyda tarequest.com.

\section{Ethics approval and consent to participate}

This is a subgroup analysis and summary of data from the DREAM, SIRIUS, MENSA, MUSCA and COSMOS trials, all of which were conducted in accordance with the ethical principles of the Declaration of Helsinki, International Council for Harmonization Good Clinical Practice (GCP) and the applicable country-specific regulatory ethics requirements in individual countries.

\section{Consent for publication}

Not applicable.

\section{Competing interests}

SWY, ONK, and ESB are GSK employees and hold GSK stocks/shares. HGO was an employee of GSK during the time of the analysis and is now employed by Gossamer Bio.

\section{Author details}

1 Respiratory Therapeutic Area, GSK, 5 Moore Drive, PO Box 13398, Research Triangle Park, NC 27709, USA. ${ }^{2}$ Respiratory US Medical Affairs, GSK, La Jolla, CA USA. ${ }^{3}$ Clinical Statistics, GSK, Stockley Park, Middlesex, UK. ${ }^{4}$ Present Address: GossamerBio, San Diego, CA, USA.

Received: 14 December 2018 Accepted: 23 August 2019

Published online: 03 September 2019

\section{References}

1. Sears MR. Descriptive epidemiology of asthma. Lancet. 1997;350(Suppl 2):Sii1-4.

2. Lee YJ, Kim KW, Choi BS, Sohn MH, Kim KE. Clinical characteristics of eosinophilic and noneosinophilic asthma in children. Acta Paediatr. 2013;102(1):53-7.

3. Chipps BE, Szefler SJ, Simons FE, Haselkorn T, Mink DR, Deniz Y, et al. Demographic and clinical characteristics of children and adolescents with severe or difficult-to-treat asthma. J Allergy Clin Immunol. 2007;119(5):1156-63.

4. Lovett CJ, Whitehead BF, Gibson PG. Eosinophilic airway inflammation and the prognosis of childhood asthma. Clin Exp Allergy. 2007:37(11):1594-601.

5. Dolan CM, Fraher KE, Bleecker ER, Borish L, Chipps B, Hayden ML, et al. Design and baseline characteristics of the epidemiology and natural history of asthma: outcomes and Treatment Regimens (TENOR) study: a large cohort of patients with severe or difficult-to-treat asthma. Ann Allergy Asthma Immunol. 2004;92(1):32-9.

6. Fitzpatrick AM, Baena-Cagnani CE, Bacharier LB. Severe asthma in childhood: recent advances in phenotyping and pathogenesis. Curr Opin Allergy Clin Immunol. 2012;12(2):193-201.

7. Manson SC, Brown RE, Cerulli A, Vidaurre CF. The cumulative burden of oral corticosteroid side effects and the economic implications of steroid use. Respir Med. 2009;103(7):975-94.

8. Bleecker ER, FitzGerald JM, Chanez P, Papi A, Weinstein SF, Barker P, et al. Efficacy and safety of benralizumab for patients with severe asthma uncontrolled with high-dosage inhaled corticosteroids and long-acting beta2-agonists (SIROCCO): a randomised, multicentre, placebo-controlled phase 3 trial. Lancet. 2016;388(10056):2115-27.

9. FitzGerald JM, Bleecker ER, Nair P, Korn S, Ohta K, Lommatzsch M, et al. Benralizumab, an anti-interleukin-5 receptor alpha monoclonal antibody, as add-on treatment for patients with severe, uncontrolled, eosinophilic asthma (CALIMA): a randomised, double-blind, placebo-controlled phase 3 trial. Lancet. 2016;388(10056):2128-41.

10. Centers for Disease Control and Prevention. Asthma-related missed school days among children aged 5-17 years. 2013. https://www.cdc. gov/asthma/asthma_stats/AstStatChild_Missed_School_Days.pdf. Accessed 14 Dec 2018.

11. Bender B, Wamboldt FS, O'Connor SL, Rand C, Szefler S, Milgrom H, et al. Measurement of children's asthma medication adherence by self report, mother report, canister weight, and Doser CT. Ann Allergy Asthma Immunol. 2000;85(5):416-21.

12. Rhee $H$, Belyea MJ, Ciurzynski S, Brasch J. Barriers to asthma selfmanagement in adolescents: relationships to psychosocial factors. Pediatr Pulmonol. 2009;44(2):183-91.

13. Taddeo D, Egedy M, Frappier JY. Adherence to treatment in adolescents. Paediatr Child Health. 2008;13(1):19-24.

14. Ortega HG, Liu MC, Pavord ID, Brusselle GG, FitzGerald JM, Chetta A, et al. Mepolizumab treatment in patients with severe eosinophilic asthma. N Engl J Med. 2014;371(13):1198-207.

15. Chupp GL, Bradford ES, Albers FC, Bratton DJ, Wang-Jairaj J, Nelsen LM, et al. Efficacy of mepolizumab add-on therapy on health-related quality of life and markers of asthma control in severe eosinophilic asthma (MUSCA): a randomised, double-blind, placebo-controlled, parallelgroup, multicentre, phase 3b trial. Lancet Respir Med. 2017;5(5):390-400.

16. Pavord ID, Korn S, Howarth P, Bleecker ER, Buhl R, Keene ON, et al. Mepolizumab for severe eosinophilic asthma (DREAM): a multicentre, double-blind, placebo-controlled trial. Lancet. 2012;380(9842):651-9. 
17. Bel EH, Wenzel SE, Thompson PJ, Prazma CM, Keene ON, Yancey SW, et al. Oral glucocorticoid-sparing effect of mepolizumab in eosinophilic asthma. N Engl J Med. 2014;371(13):1189-97.

18. Brusselle GG, Maes T, Bracke KR. Eosinophils in the spotlight: eosinophilic airway inflammation in nonallergic asthma. Nat Med. 2013;19(8):977-9.

19. Lugogo N, Domingo C, Chanez P, Leigh R, Gilson MJ, Price RG, et al. Long-term efficacy and safety of mepolizumab in patients with severe eosinophilic asthma: a multi-center, open-label, phase IIIb study. Clin Ther. 2016;38(9):2058-70 e1.

\section{Publisher's Note}

Springer Nature remains neutral with regard to jurisdictional claims in published maps and institutional affiliations.
Ready to submit your research? Choose BMC and benefit from:

- fast, convenient online submission

- thorough peer review by experienced researchers in your field

- rapid publication on acceptance

- support for research data, including large and complex data types

- gold Open Access which fosters wider collaboration and increased citations

- maximum visibility for your research: over $100 \mathrm{M}$ website views per year

At BMC, research is always in progress.

Learn more biomedcentral.com/submissions 